\title{
Limitations of Adenoviral Vector-Mediated Delivery of Gold Nanoparticles to Tumors for Hyperthermia Induction
}

\author{
Vaibhav Saini ${ }^{1,2,5}$, Dmitri V. Martyshkin ${ }^{3}$, Victoria D. Towner ${ }^{1}$, Sergey B. Mirov ${ }^{3}$ and \\ Maaike Everts*,1,4
}

${ }^{I}$ Division of Human Gene Therapy, Departments of Medicine, Obstetrics and Gynecology, Pathology, Surgery, and the Gene Therapy Center; ${ }^{2}$ Department of Physiology and Biophysics; ${ }^{3}$ Department of Physics; ${ }^{4}$ Division of Molecular and Cellular Pathology, Pathology, University of Alabama at Birmingham, Birmingham, Alabama, ${ }^{5}$ Screening Technologies Branch, Developmental Therapeutics Program, National Cancer Institute at Frederick, Frederick, Maryland

\begin{abstract}
Novel combinatorial treatment strategies are desired to achieve tumor eradication. In this regard, nanotechnology and gene therapy hold the potential to expand the available tumor treatment options. In particular, gold nanoparticles (AuNPs) have been utilized for hyperthermic tumor cell ablation. Similarly, adenoviral (Ad) vectors have been utilized for targeting, imaging, and cancer gene therapy. Thus, to combine AuNP-mediated hyperthermia with Ad vector-based gene therapy, we have previously coupled AuNPs to Ad vectors. Herein we tested the capability of these AuNP-coupled Ad vectors for hyperthermic tumor cell ablation. Towards this end, we compared absorption characteristics of different sized AuNPs and determined that in our system $20 \mathrm{~nm}$ diameter AuNPs are suitable for laser induced hyperthermic tumor cell killing. In addition, we observed that AuNPs outside and inside the cell contribute differentially towards hyperthermia induction. Unfortunately, due to the limitation of delivery of required amounts of AuNPs to cells, we observed that AuNPcoupled Ad vectors are unable to kill tumor cells via hyperthermia. However, with future technological advances, it may become possible to realize the potential of the multifunctional AuNP-coupled Ad vector system for simultaneous targeting, imaging, and combined hyperthermia and gene therapy of tumors.
\end{abstract}

Keywords: Gold nanoparticles, hyperthermia, tumor treatment, adenovirus.

\section{INTRODUCTION}

Development of new treatment options is crucial to achieve tumor eradication. In this regard, nanotechnology and gene therapy can provide novel opportunities for cancer therapy. For example, in nanotechnology, gold nanoparticles (AuNPs) have been shown to be useful for drug delivery, targeting, imaging, and hyperthermia therapy of tumors [18]. In particular, laser-heated AuNPs have been shown to be effective in killing the tumors via hyperthermia induction, which possibly perturbs the tumor cell machinery at both the genetic and protein level, resulting in cell death [9-11]. Similarly, in gene therapy, adenoviral (Ad) vectors have been developed as multifunctional therapeutic agents, providing applications such as targeting, imaging, and tumor cell killing [12].

With regards to tumor ablation, a combinatorial therapeutic regimen, as opposed to a single component therapy, has been recognized as optimal for successful treatment. In this regard, radiotherapy, chemotherapy, and immunotherapy approaches have been combined with gene therapy for developing more effective tumor ablation strategies [13-15]. Based on this, we have previously proposed to combine nanotechnology-based treatment opportunities with gene therapy for developing novel multifunctional nanoparticles

*Address correspondence to this author at the Assistant Professor, BMRII\#512, 901 19th Street South, Birmingham, AL 35294-2180, USA; Tel: 1205-975-7288, 1-205-975-2960; Fax: 1-205-975-7949;

E-mail: maaike@uab.edu for tumor treatment [16]. To this end, we have combined two independent therapeutic modalities into a single nano agent for tumor treatment by coupling AuNPs to Ad vectors without perturbing the biological interactions of Ad vectors with target cells $[17,18]$. The AuNP-coupled Ad vector nano agent could be used to explore the possibility of combining gene therapy with AuNP based hyperthermia for the treatment of cancer $[17,18]$. In the current study, we tested the feasibility of utilizing these AuNP-coupled Ad vectors for hyperthermia therapy.

\section{MATERIALS AND METHODOLOGY}

\section{Cell Culture}

HeLa cells were obtained from the American Type Culture Collection (ATCC, Manassas, VA, USA) and HEK-293 cells were obtained from Microbix (Toronto, Canada). The cells were maintained in DMEM:Ham's F12 (1:1 v/v, Mediatech, Herndon, VA) medium, containing $10 \%$ fetal bovine serum (Hyclone, Logan, UT), 2 nM L-glutamine, $100 \mathrm{IU} / \mathrm{mL}$ penicillin and $25 \mu \mathrm{g} / \mathrm{mL}$ streptomycin (all Mediatech) and were grown in a humidified atmosphere with $5 \% \mathrm{CO}_{2}$ at $37^{\circ} \mathrm{C}$.

\section{Ad Vector Production}

The Ad vectors encoding a red fluorescence protein (DsRed) under transcriptional control of the constitutively active cytomegalovirus (CMV) promoter and displaying a biotin acceptor peptide (BAP) in hexon (HVR5) were kindly provided by Dr. Michael A Barry (Mayo Clinic, Rochester, 
Minnesota, USA). For virus production, HEK-293 cells were infected using growth medium containing $2 \%$ fetal bovine serum instead of $10 \%$. Following overnight incubation, regular medium was added to the cells and they were incubated until cytopathic effect was observed. Cells were harvested and lysates were obtained by 4 consecutive freeze-thaw cycles. Virus was purified using standard double $\mathrm{CsCl}$ gradient ultracentrifugation. Viral particle number was determined by measuring absorbance at $260 \mathrm{~nm}$ using a conversion factor of $1.1 \times 10^{12}$ viral particles per absorbance unit [19]. The biotinylation status of the purified viral particles was determined via western blot (data not shown).

\section{AuNPs}

AuNPs with a diameter of $1.8 \mathrm{~nm}$ containing a Ni-NTA reactive group on the surface of the particle were acquired from Nanoprobes (Yaphank, NY, USA) and AuNPs with a diameter of $5 \mathrm{~nm}$ and $20 \mathrm{~nm}$ containing a streptavidin reactive group on the surface of the particle were acquired from Nanocs (New York, NY, USA). The coupling of $5 \mathrm{~nm}$ and $20 \mathrm{~nm}$ diameter AuNPs with biotinylated Ad vectors was carried out at a ratio of 280:1 (AuNPs:Ad) for 30 minutes at room temperature, prior to adding the mixture to HeLa cells.

\section{Absorption Spectra Measurements}

The absorption spectra of $1.8 \mathrm{~nm}, 5 \mathrm{~nm}$, and $20 \mathrm{~nm}$ AuNPs were measured in $0.5 \mathrm{~cm}$ quartz spectroscopic cell using UV-VIS-NIR scanning spectrophotometer (Shimazdu UV-3101PC). Absorption cross section $\left(\sigma, \mathrm{cm}^{2}\right)$ was calculated according to Lambert-Beer law $T=I_{1} / I_{0}=e^{-\sigma n l}$, or $\sigma=\ln (1 / T) / n l$, where $T$ is transmission coefficient, $I_{0}$ and $I_{l}$ is incident and transmitted light intensities, $n$ is concentration (nanoparticles per $\mathrm{mL}$ ), and $l$ is a spectroscopic cell length in $\mathrm{cm}$.

\section{Laser Treatment}

Cells incubated with AuNPs: HeLa cells were plated in triplicates at a density of 50,000 cells/well in $1 \mathrm{ml}$ glass shell vials with a $6 \mathrm{~mm}$ internal diameter (Wheaton, NJ, USA). The following day, cells were rinsed with PBS and incubated with AuNPs in medium containing 2\% fetal bovine serum for 1 hour at $37^{\circ} \mathrm{C}$. Cells were either washed with PBS or not, as indicated in the description of the respective experimental results.

Cells incubated with AuNPs and Ad vectors: HeLa cells were plated as described above. The following day, cells were incubated with AuNPs and/or Ad vectors for 1 hour at $4^{\circ} \mathrm{C}$, then washed with PBS or not, and subsequently incubated for another hour at $37^{\circ} \mathrm{C}$, and again either washed with PBS or not.

Following the incubations, cells were laser irradiated at $532 \mathrm{~nm}, 600$ pulses, 1 minute, 4.2-5.2 W. After irradiation, cells were incubated in a humidified atmosphere with $5 \%$ $\mathrm{CO}_{2}$ at $37{ }^{\circ} \mathrm{C}$ for 1 hour, and then trypsinized before being stained with propidium iodide, $25 \mu \mathrm{g} / \mathrm{ml}$ (Invitrogen, Carlsbad, CA) before being subjected to flow cytometry (Fig. 7).

\section{Statistics}

Statistical analysis for significance was performed using a 2-tailed student's t-test assuming equal variance in Excel
(Microsoft Office 2003) and a p value of $<0.05$ was considered significant.

\section{RESULTS}

\section{Small-Sized AuNPs are Unable to Induce Laser- Mediated Hyperthermic Tumor Cell Ablation}

In previously published reports $[17,18]$, we have coupled AuNPs of 1.3 and $1.8 \mathrm{~nm}$ diameter to Ad vectors to demonstrate the principle of coupling metal NPs to gene therapy vectors that could potentially facilitate combination therapy of neoplastic disease. Various types and sizes of AuNPs have been used for hyperthermic tumor cell killing by several groups $[2-5,7]$. Therefore, before using AuNP-coupled vectors for $532 \mathrm{~nm}$-laser induced hyperthermic tumor cell ablation, we tested the suitability of our previously used $1.8 \mathrm{~nm}$ diameter AuNPs for this purpose. To this end, we compared the absorption characteristics of $1.8 \mathrm{~nm}$ NPs with other NPs and observed that at $532 \mathrm{~nm}$, the absorption cross section of $1.8 \mathrm{~nm}$ NPs is 100 and 1000 times less than $5 \mathrm{~nm}$ and $20 \mathrm{~nm}$ NPs respectively (Fig. 1).

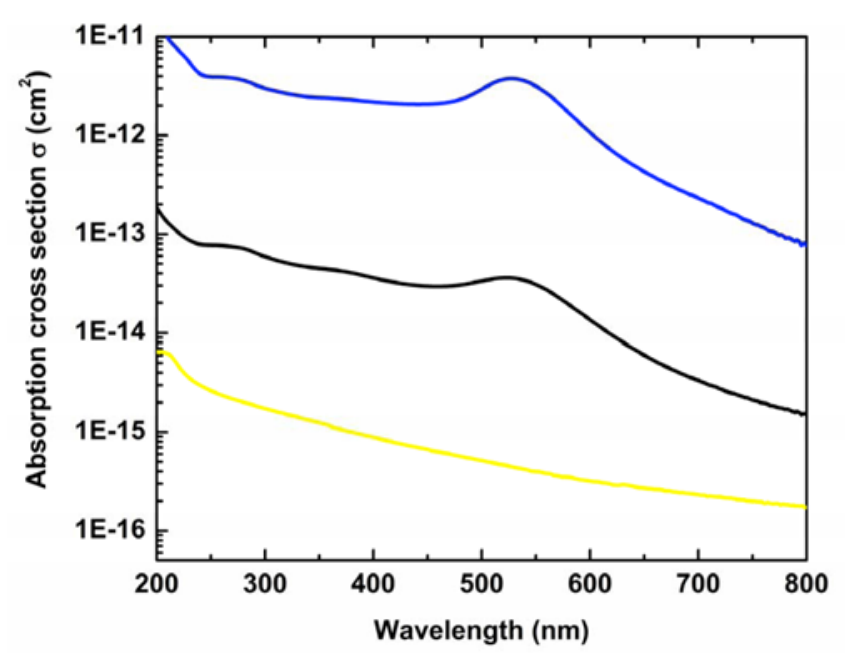

Fig. (1). Absorption coefficients of different sized AuNPs: 1.8 $\mathrm{nm}$ (yellow line), $5 \mathrm{~nm}$ (black line), and $20 \mathrm{~nm}$ (blue line). The higher the absorption cross section of a NP, the higher the capability of that NP to increase temperature, and thus, the higher the suitability to cause hyperthermia. $20 \mathrm{~nm}$ and $5 \mathrm{~nm}$ NPs absorb 1000 times and 100 times more than $1.8 \mathrm{~nm}$ NPs at $532 \mathrm{~nm}$, and thus, these bigger NPs could be more suitable for hyperthermia induction.

Based on the low absorption efficiency of $1.8 \mathrm{~nm}$ NPs, we hypothesized that these NPs might not be suitable for hyperthermic tumor cell killing. To test our hypothesis, we used the experimental set-up based upon a previously published system with minor modifications, including a higher power setting $(\sim 5 \mathrm{~W}$ vs. $1.9 \mathrm{~W})$, and a longer pulse duration (60 seconds vs. 10 seconds) [7]. Also, to mimic a solid tumor for which hyperthermia therapy would be useful, we irradiated surface-attached cells in a monolayer instead of cells in suspension. The irradiation procedure itself had no negative impact on cell viability, as compared to control cells (Fig. 2a and b). In addition, AuNPs incubated with HeLa cells in the absence of irradiation had no negative impact on cell viability (Fig. 2g). Moreover, upon incubation of HeLa cells with 


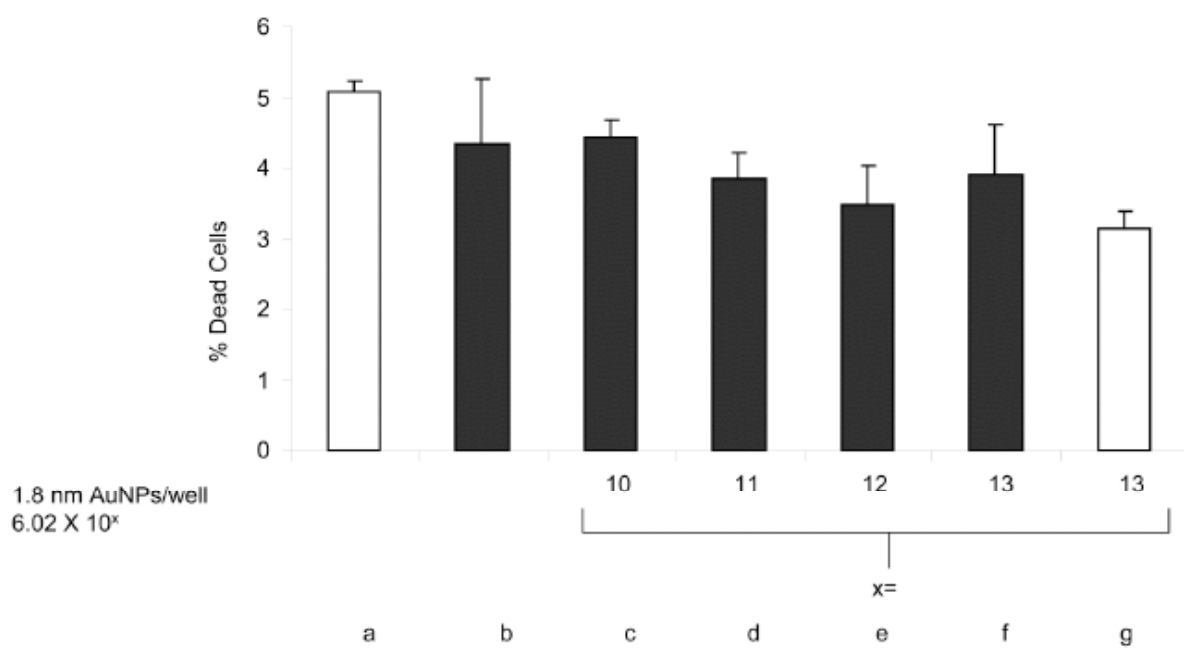

Fig. (2). AuNPs of $1.8 \mathrm{~nm}$ diameter are unable to induce hyperthermic tumor cell (HeLa) ablation upon laser irradiation. Nonirradiated (white bars) and irradiated (black bars, $532 \mathrm{~nm}, 600$ pulses, 1 minute, $5.2 \mathrm{~W}$ ). The irradiation procedure itself (b) and AuNPs without irradiation (g) had no negative impact on cell viability as compared to control cells (a and b). Incubation with AuNPs ranging from 6.02 $\mathrm{X} 10^{10}$ to $6.02 \mathrm{X} 10^{13} \mathrm{NPs}$ per well in combination with laser irradiation did not change cell viability (c-f).

AuNP numbers ranging from $6.02 \times 10^{10}$ to $6.02 \times 10^{13}$ per well in combination with laser irradiation, no change in cell viability was observed (Fig. 2c-f). Thus, as expected, $1.8 \mathrm{~nm}$ AuNPs were unable to induce hyperthermic tumor cell death.

\section{AuNPs of 20 nm Diameter Can Induce Laser-Mediated Hyperthermic Tumor Cell Ablation}

After observing the higher absorption cross section at $532 \mathrm{~nm}$ for 5 and $20 \mathrm{~nm}$ diameter AuNPs as compared to 1.8 nm AuNPs, we tested the capability of these bigger NPs for laser-induced hyperthermic tumor cell killing. As observed before, the irradiation procedure had no negative impact on cell viability as compared to the control cells (Fig. 3a and b). Also, the maximum number of $5 \mathrm{~nm}$ (Fig. 3f) and $20 \mathrm{~nm}$ (Fig. 3j) AuNPs incubated with HeLa cells in the absence of irradiation had no negative impact on cell viability. In addition, when $5 \mathrm{~nm}$ AuNPs were incubated with HeLa cells in numbers ranging from $5 \times 10^{9}$ to $5 \times 10^{11} \mathrm{NPs}$ per well, and



Fig. (3). AuNPs of $20 \mathrm{~nm}$ diameter can kill tumor cells (HeLa) via laser-induced hyperthermia. Non-irradiated (white bars) and irradiated (black bars, $532 \mathrm{~nm}, 600$ pulses, 1 minute, $4.2 \mathrm{~W}$ ). The irradiation procedure itself (b) and the maximum number of AuNPs of $5 \mathrm{~nm}$ (f) and $20 \mathrm{~nm}$ (j) without irradiation had no negative impact on cell viability as compared to control cells (a and b). Incubation with $5 \mathrm{~nm}$ AuNPs ranging from $5 \times 10^{9}$ to $5 \times 10^{11}$ NPs per well (c-e) and with $20 \mathrm{~nm}$ AuNPs at either 7 X $10^{8}$ or 7 X $10^{9}$ NPs per well (g and h) in combination with laser irradiation did not change cell viability. However, incubation with $7 \times 10^{10}$ AuNPs of $20 \mathrm{~nm}$ per well in combination with laser irradiation resulted in a significant hyperthermic cell death of $50.3 \pm 13.6 \%$ (i). * indicates $\mathrm{p}<0.05$. 


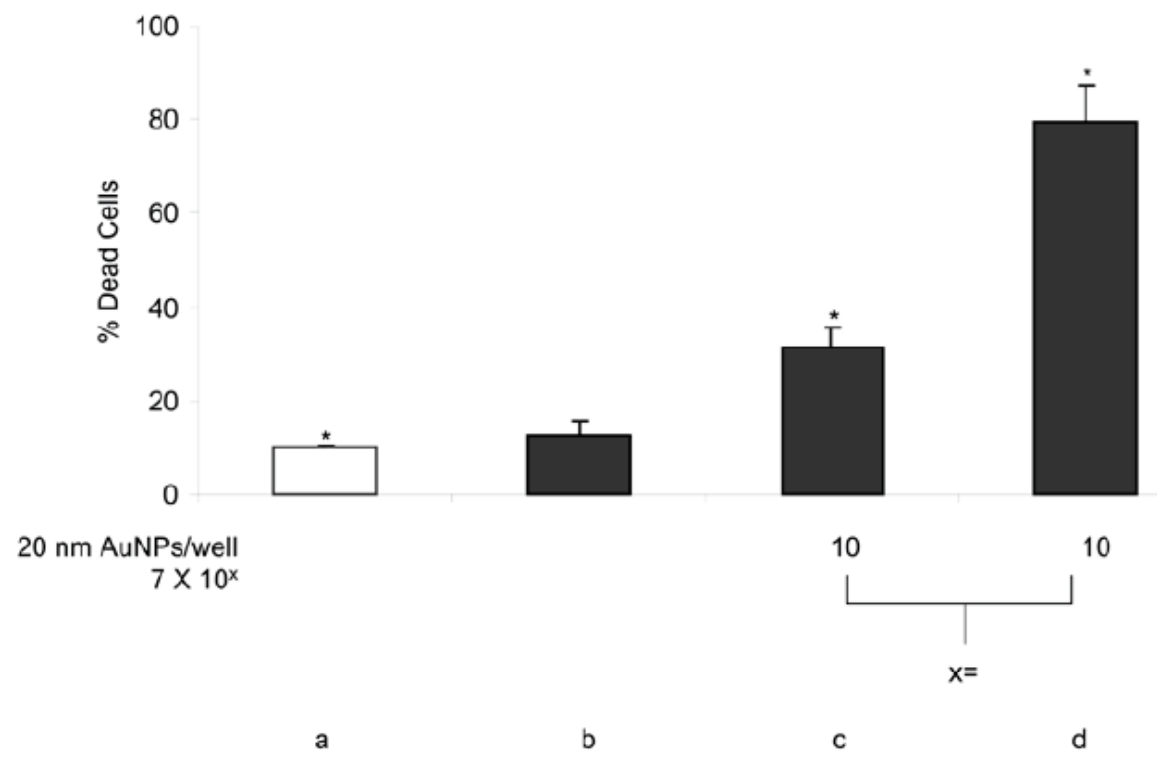

Fig. (4). AuNPs on the surface and inside the HeLa cells contribute to laser-induced hyperthermic cell killing. Non-irradiated (white bars) and irradiated (black bars, $532 \mathrm{~nm}, 600$ pulses, 1 minute, $4.5 \mathrm{~W}$ ). The irradiation procedure itself (b) had no negative impact on cell viability as compared to control cells (a). Cells were incubated with 7 X $10^{10}$ AuNPs of $20 \mathrm{~nm}$ diameter at $37^{\circ} \mathrm{C}$ for 1 hour, then either washed twice with PBS to remove both the unbound AuNPs in solution and the non-internalized AuNPs attached to the cell surface, leaving only the internalized AuNPs in cells (c) or not washed (d). Subsequently, these samples were irradiated. Though more cell death (79.8 \pm 7.6 $\%$ ) was observed in the sample that was not washed (d), the washed sample (c) also had significant cell death (31.6 $\pm 4.0 \%)$ as compared to the control (a). * indicates $\mathrm{p}<0.05$.

subsequently laser irradiated, no change in cell viability was observed (Fig. 3c-e). Similarly, $20 \mathrm{~nm}$ AuNPs did not change HeLa cell viability at either $7 \times 10^{8}$ or $7 \times 10^{9}$ AuNPs per well (Fig. 3g and h). However, when HeLa cells were incubated with 7 X $10^{10}$ AuNPs of $20 \mathrm{~nm}$ per well, and then laser irradiated, a significant hyperthermic cell death of $50.3 \pm 13.6 \%$ was observed (Fig. 3i). Of note, besides $1.8 \mathrm{~nm}$, $5 \mathrm{~nm}$, and $20 \mathrm{~nm}$ NPs, we also analyzed the ability of $40 \mathrm{~nm}$ AuNPs to induce cell killing upon laser irradiation, and found them to be less able to do so than 20-nm AuNPs in our system (data not shown).

After observing cell death with $20 \mathrm{~nm}$ diameter AuNPs, we wanted to discern whether AuNPs should be located either on the surface or inside the cell for hyperthermia induction. To characterize this differential contribution of NPs, we analyzed cell death with or without washing the cells after incubating them with $7 \times 10^{10}$ AuNPs of $20 \mathrm{~nm}$ diameter. It has been reported in the literature that cells internalize AuNPs [20]. Thus, after incubating the cells with AuNPs at $37^{\circ} \mathrm{C}$ for 1 hour, washing removes both the unbound AuNPs in solution and the non-internalized AuNPs attached to the cell surface, leaving only the internalized AuNPs in cells. Although we observed more cell death $(79.8 \pm 7.6 \%)$ in the sample that was not washed, the washed sample also had significant cell death $(31.6 \pm 4.0 \%)$ as compared to the control (Fig. 4a, c and d). This indicates that AuNPs in the solution and on the surface as well as inside the cells contribute to hyperthermic killing.

\section{Analysis of Ad Vectors Coupled with $20 \mathrm{~nm}$ Diameter AuNPs for Hyperthermic Cell Killing}

After determining the suitability of $20 \mathrm{~nm}$ AuNPs for 532 $\mathrm{nm}$ laser-induced hyperthermic cell killing, we proceeded to analyze whether $20 \mathrm{~nm}$ AuNP-coupled Ad vectors could be utilized for cell killing as well, as this would pave the way for combining AuNP-mediated hyperthermia with Ad vector mediated gene therapy of tumors. Towards this end, we coupled streptavidin-functionalized $20 \mathrm{~nm}$ AuNPs to genetically engineered Ad vectors that are metabolically biotinylated in the hexon capsid protein. This coupling method is conceptually based upon the specific coupling strategy published previously, where $1.8 \mathrm{~nm} \mathrm{Ni-NTA-AuNPs}$ were specifically coupled to Ad vectors expressing a 6-His in hexon [18]. However, due to the bigger size of AuNPs (20 nm vs 1.8 $\mathrm{nm}$ ), we were unable to use the previously employed $\mathrm{CsCl}$ density gradient ultracentrifugation for separating the reactants from the products. Thus, in order to separate unreacted AuNPs from the AuNP-coupled Ad vectors, we utilized the principle of viral interaction with its receptor-coxsackie adenovirus receptor (CAR). While Ad vectors can bind to CAR at $4{ }^{\circ} \mathrm{C}$ [21], AuNPs have not been observed to bind to a specific receptor, and therefore should not interact with the cells at this temperature. We therefore incubated the mixture of unreacted AuNPs and AuNP-coupled Ad vectors with HeLa cells, which express CAR, at $4^{\circ} \mathrm{C}$ for 1 hour, and then upon washing removed both unreacted AuNPs and excess AuNP-coupled Ad vectors that had not bound to the cells (Fig. 5). To confirm whether washing removes AuNPs after incubation at $4^{\circ} \mathrm{C}$ for 1 hour, we incubated HeLa cells with 7 X $10^{10}$ AuNPs of $20 \mathrm{~nm}$ diameter at $4^{\circ} \mathrm{C}$ for 1 hour, then washed twice with PBS, and subsequently irradiated; as expected, the cell viability was the same as that observed when cells were not treated with AuNPs (Fig. 6b and d). Unfortunately, when cells were incubated with AuNPs coupled to Ad vectors, no significant cell death was observed (Fig. 6g). To understand this inability of AuNP-coupled Ad vectors for hyperthermic cell killing, we theoretically calculated the 

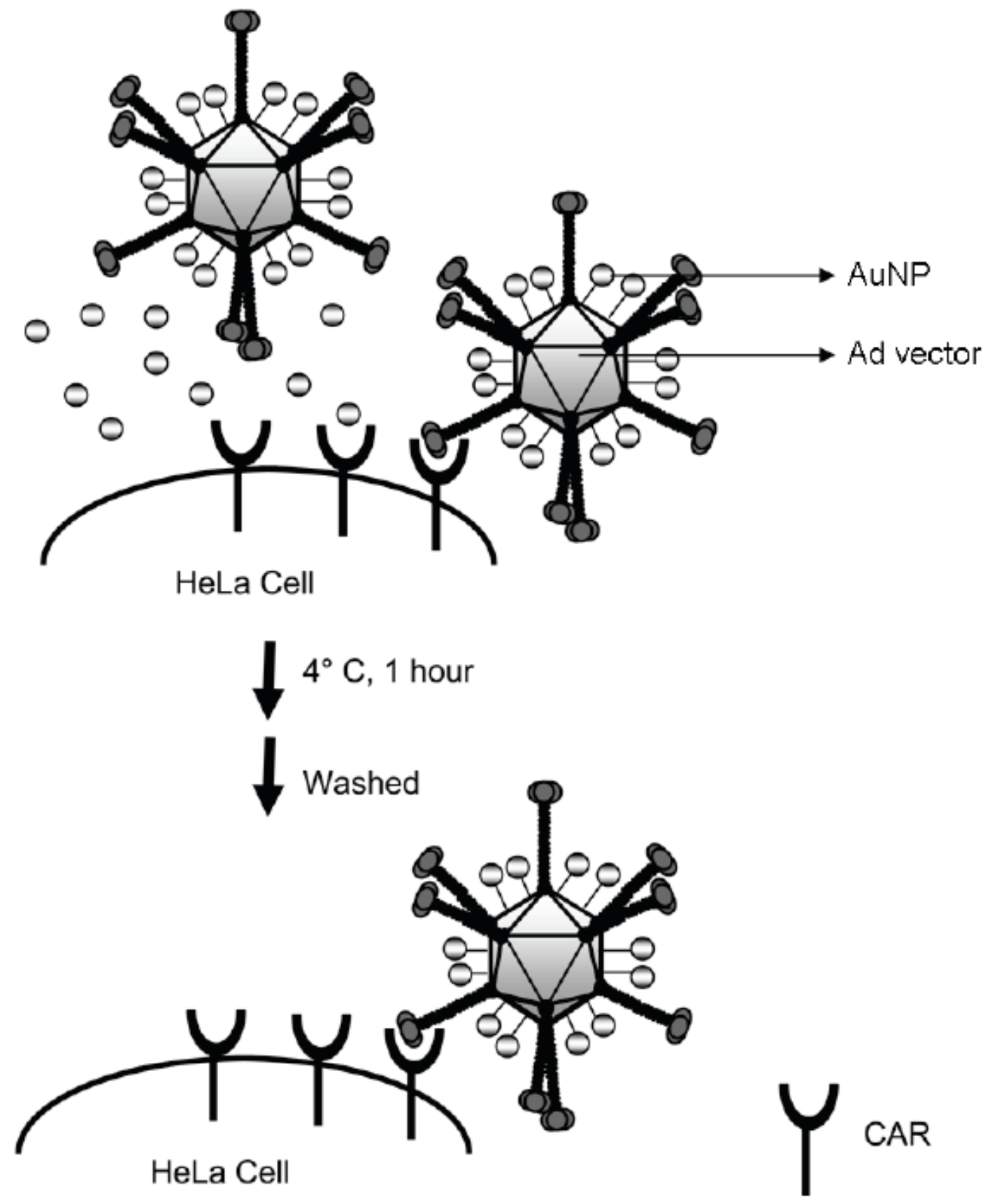

Fig. (5). Cellular binding of Adenovirus and AuNPs is temperature dependent. While Ad vectors can bind to $\mathrm{CAR}$ at $4^{\circ} \mathrm{C}$, AuNPs have not been reported to bind to a specific receptor, and therefore should not interact with the cells at $4^{\circ} \mathrm{C}$. We incubated the mixture of unreacted AuNPs and AuNP-coupled Ad vectors with CAR expressing HeLa cells at $4^{\circ} \mathrm{C}$ for 1 hour. Subsequent washing removed both unreacted AuNPs and AuNP-coupled Ad vectors that did not bind to the CAR.

maximum number of AuNPs that can be delivered to cells utilizing Ad vectors. We plated 50,000 HeLa cells per well and infected these with Ad vectors at a multiplicity of infection (MOI) of $5000 \mathrm{vp} / \mathrm{cell}$. Thus, we added $2.5 \times 10^{8}$ $\mathrm{vp} /$ well. If only $10 \%$ of these added viral particles infect cells, then the number of Ad vectors infecting cells per well is $2.5 \times 10^{7}$. In a previously published report, we were able to couple 56 \pm 4 AuNPs of $1.8 \mathrm{~nm}$ diameter to Ad vectors [18]. Most likely, steric factors restrict the number of $20 \mathrm{~nm}$ AuNPs that can be coupled to Ad vectors. We anticipate that this number is less than the number of $1.8 \mathrm{~nm}$ AuNPs that can be coupled per virus. In this regard, Ad vectors have 20 triangular facets, each formed by 12 copies of hexon trimers
[22]. Based on this, we hypothesized that we could couple 20 AuNPs of $20 \mathrm{~nm}$ diameter to each Ad vector (1 AuNP per facet), resulting in the delivery of $5 \times 10^{8}$ AuNPs to the cells per well by Ad vectors. This number is approximately $100 \mathrm{X}$ less that the number needed for inducing laser-mediated hyperthermic tumor cell ablation. To confirm the inability of 5 x $10^{8}$ AuNPs/well to induce cell killing, we incubated HeLa cells with $5 \times 10^{8}$ AuNPs/well and did not observe cell death (Fig. 6f). Thus, although $20 \mathrm{~nm}$ AuNPs can be utilized for hyperthermic tumor cell killing, it is presently not possible to deliver the required number of AuNPs to the tumor cells utilizing Ad vectors. 


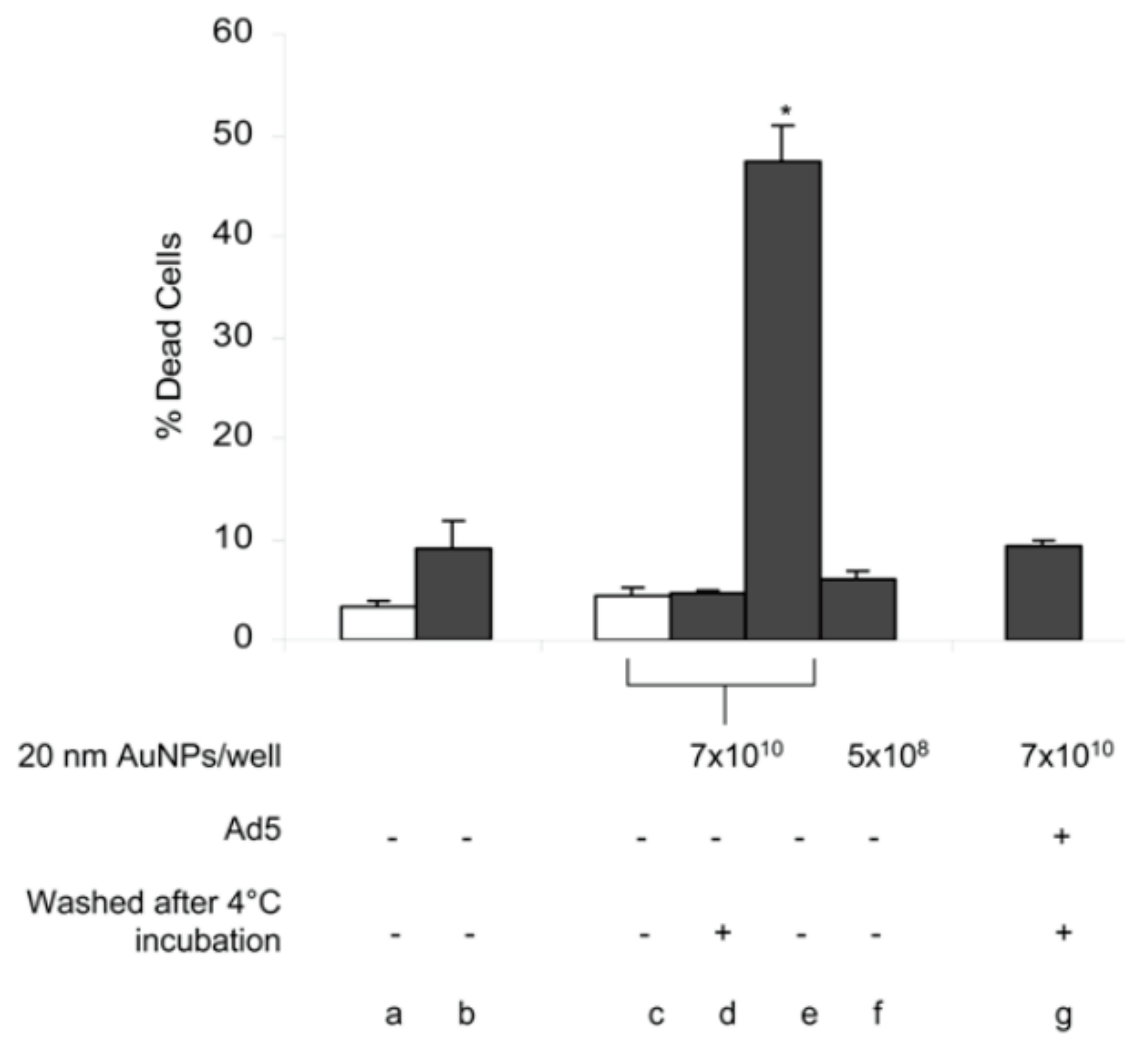

Fig. (6). AuNP-coupled Ad5 vectors unable to induce laser-mediated hyperthermic tumor cell ablation. Non-irradiated (white bars) and irradiated (black bars, $532 \mathrm{~nm}, 600$ pulses, 1 minute, $4.5 \mathrm{~W}$ ). The irradiation procedure itself (b) and the maximum number of AuNPs of 20 $\mathrm{nm}$ (c) without irradiation had no negative impact on cell viability as compared to control cells (a). Incubation of HeLa cells with 7 X $10^{10}$ AuNPs of $20 \mathrm{~nm}$ diameter at $4^{\circ} \mathrm{C}$ for 1 hour followed by washing (twice, PBS) and irradiation (d) resulted in the same cell viability as that observed when cells were not treated with AuNPs (b). Incubation with 7 X $10^{10}$ AuNPs of $20 \mathrm{~nm}$ per well in combination with laser irradiation resulted in a significant hyperthermic cell death (e). Unfortunately, incubation of cells with AuNP-coupled Ad vectors did not change cells viability $(\mathrm{g})$. We hypothesized that this inability of AuNP-coupled Ad vectors could be because of the lower number of AuNPs $\left(5 \mathrm{x} 10^{8}\right.$ $\mathrm{NP} /$ well) delivered by these vectors. This hypothesis was confirmed by incubation of HeLa cells with 5 x $10^{8}$ AuNPs/well, which did not change cell viability (f). * indicates $\mathrm{p}<0.05$.

\section{DISCUSSION}

A combinatorial approach has been recognized as optimal for successful tumor treatment. Thus, to combine nanotechnology with gene therapy for developing a novel nanoscale agent for cancer therapy, we have previously coupled AuNPs to Ad vectors [17, 18]. In the current study, we explored the feasibility of utilizing these AuNP-coupled Ad vectors for hyperthermic tumor cell ablation.

The rapid multiplication of tumor cells imposes disadvantages on these cells, which can be utilized for selective therapeutic intervention for killing the neoplastic cells while restricting the damage to the healthy cells of the body. In this regard, due to the limited vasculature, resulting in a hypoxic environment and a low $\mathrm{pH}$, tumors are inefficient in counteracting an increase in temperature, which disrupts the cell machinery at the molecular level [9-11]. Thus tumors are prone to hyperthermia induced cell death as reported in the literature using laser-heated AuNPs [2-5, 7, 23].

Our results demonstrate that the hyperthermic cell killing ability of AuNPs is a function of their size and amount associated with the cells, which is analogous to previously published reports $[7,24]$. In addition, as reported previously [17, 18], while Ad vectors can be used to deliver AuNPs to tu- mors, we discovered that current technological limitations restrict our ability to deliver the required amount of AuNPs to tumors to induce hyperthermic cell death.

The observed inefficiency of AuNP-coupled Ad vectors can theoretically be countered by improvements in the AuNP payload capacity of the Ad vector, the number of Ad vectors bound to the tumor cell, the physical characteristics of the AuNPs themselves, and/or utilizing a different laser irradiation regime. With regards to Ad vectors, increasing the number of AuNPs coupled to Ad vectors would increase the number of AuNPs delivered to target cells. However, with the coupling strategies reported by our group, it is currently not possible to attach more NPs to Ad vectors. For example, with the non-specific coupling of AuNPs to amine groups on Ad capsid, a decrease in Ad infectivity was observed with increasing amounts of AuNPs bound to Ad vectors [17]. With specific coupling of Ni-NTA-AuNPs to Ad vectors expressing a 6-histidine (6-His) tag at different capsid locations, it is worthwhile to note that we observed AuNP coupling only to hexon, which is the most abundant protein in the Ad capsid, and not to any other surface exposed and/or abundant capsid protein like fiber or pIX [18]. In addition, in the current study, instead of Ni-NTA and 6-His, we used the affinity of streptavidin-biotin, which is among the highest 


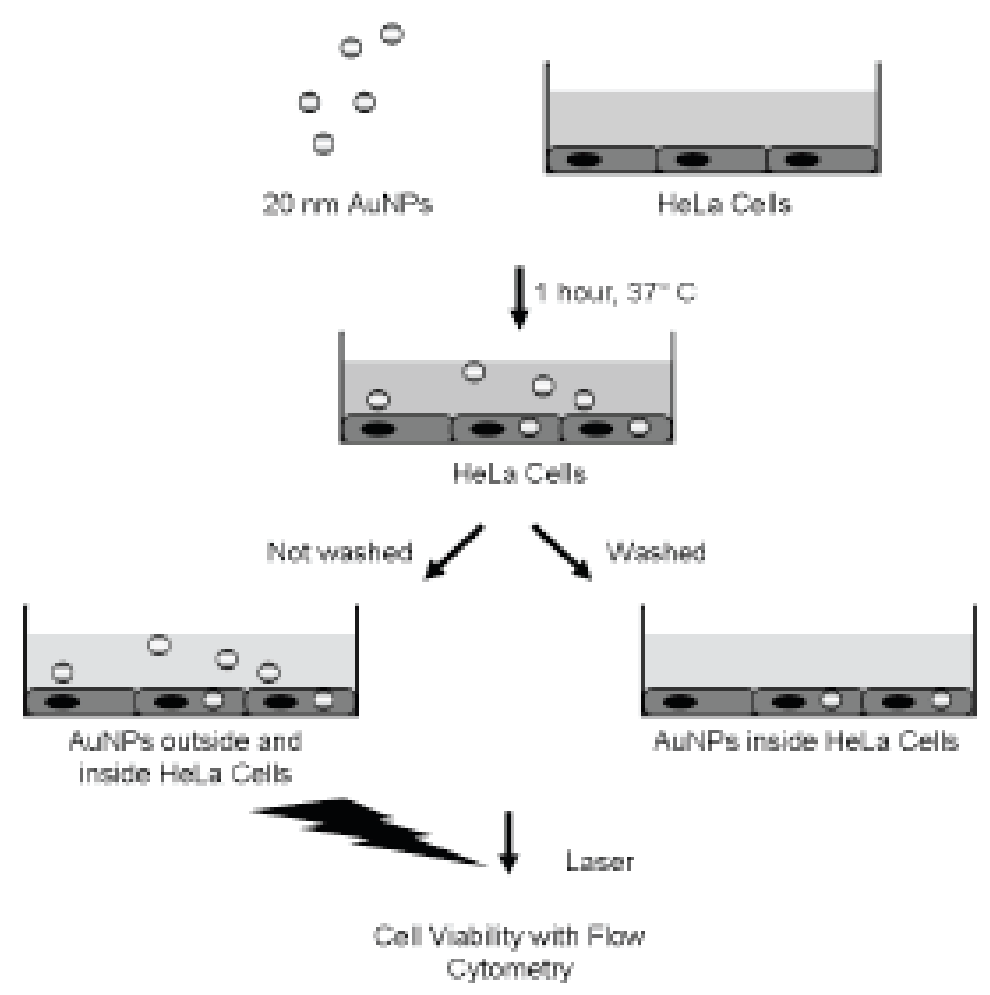

Fig. (7). Experimental set up demonstrating the steps of the laser irradiation protocol.

non-covalent affinity reported in the literature, to couple AuNPs to Ad vectors [25]. Thus, there is only a minor possibility for improvement in these non-specific and specific coupling strategies. However, a possible way to circumvent this problem could be the use of branched polymers with multiple binding sites for AuNPs, and subsequently attaching these AuNP branches to Ad vectors. However, it has been reported that coupling polymers to Ad vectors is detrimental to Ad vector infection in vitro and may be a limiting factor for using polymers for attaching more AuNPs to Ad vectors [26]. Nonetheless, coupling polymer seems to have less of an effect on infectivity in vivo, thus opening up the possibility of exploring this strategy to couple more AuNPs to Ad vectors [27]. In addition to investing in improved coupling strategies, it would be beneficial to improve Ad association with tumor cells. But, in this particular experimental setup we utilized a MOI of $5000 \mathrm{vp} / \mathrm{cell}$, which cannot easily be increased without inducing viral vector-based toxicity [28]. Though, strategies to overcome viral vector-related toxicities and immunological complications are under development, such as physical masking of the antigenic viral surface to avoid triggering innate immune system, genetic exchange of capsid components among different serotypes to avoid detection by antibodies, and generation of gutless vectors to prevent the induction of an adaptive immune response [12].

Besides manipulating Ad vectors, the properties of AuNPs could be changed to improve hyperthermia induction ability. One approach could be to change the size and shape of AuNPs. NPs bigger than $20 \mathrm{~nm}$ have been utilized in the past for hyperthermia induction [5]. However, one drawback of bigger sized NPs is the reduced clearance from the body [29]. Also, our aim is to combine NPs with viral vectors, and if vector properties such as infectivity and targeting need to be preserved, there will most likely be an upper - although currently unidentified - threshold of the size of nanoparticle that can be coupled. With regards to altering AuNP shape, Jain et al. compared gold nanospheres, nanoshells, and nanorods, and observed that nanorods, which absorb near $800 \mathrm{~nm}$, may be better than other shapes for biomedical applications such as imaging and photothermal therapy. They also estimated that gold nanorods with efficient radius $r_{\text {eff }}=11.43 \mathrm{~nm}$ are 14 times more effective absorbers at the resonance wavelength comparing to $20 \mathrm{~nm}$ nanospheres [30]. Moreover, it has been reported that AuNPs that absorb in the nearinfrared (NIR) region would be optimal for hyperthermia because normal body cells lack the chromophores to absorb this wavelength [31]. Thus, laser irradiation at NIR wavelengths will not have any adverse thermal effects on healthy cells that did not accumulate AuNPs.

In addition to modifying the Ad vectors and AuNPs, utilization of different laser irradiation conditions can also be attempted to improve the hyperthermia capability of AuNPcoupled Ad vectors. For example, we used a nanosecond laser irradiation regime. However, picosecond lasers, capable of delivering much higher peak power, could be more efficient for hyperthermia induction with AuNP-coupled Ad vectors. Another issue to consider is that laser irradiation may have negative effects on the ability of the Ad vector to induce transgene expression, thereby negatively impacting the combinatorial therapy we envision between hyperthermia induction and gene therapy approaches. Although not evaluated at this time, since we focused on the ability of the AuNPs to induce hyperthermia, we certainly intend to study those effects in future experiments. In this regard, it should be noted that it has been shown in the literature that irradiation of Ad vectors with a $1.32 \mathrm{~mm} \mathrm{Nd:YAG} \mathrm{laser} \mathrm{or} \mathrm{a} 810$ $\mathrm{nm}$ laser did abrogate transgene expression, although this effect could be ameliorated by using albumin as a protective 
agent [32]. Also, adenoviral vectors are able to withstand somewhat higher temperatures than $37^{\circ} \mathrm{C}$, making the end result dependent on the extent of hyperthermia induction achieved by laser irradiation. Therefore, to what extent the laser that we utilized as well as the irradiation conditions will affect Ad viability is unknown at this time.

Lastly, our results demonstrate that AuNPs both outside and inside the cells contribute towards hyperthermia. Thus, utilizing a mixture of internalizing and non-internalizing Ad vectors may help in loading the inside as well the outside of tumor cells with AuNP-coupled Ad vectors, and may enhance the achieved hyperthermia induction. For example, RGD motifs in the Ad vector penton capsid protein interact with integrins on the cell surface, and thereby mediate the process of Ad internalization. Thus, a mutant Ad vector with deleted RGD motifs has a defective internalizing mechanism, but is capable of binding to cells via CAR, and could potentially be used to deliver AuNPs to the cell surface [33].

In summary, our previous work established the feasibility of utilizing Ad vectors for NP delivery to target cells [17, 18]. However, at this time, various technical roadblocks, investigated in the current study, limit our ability to use these AuNP-coupled Ad vectors for hyperthermia induction for tumor therapy. Upon overcoming these hurdles with future endeavors, it may become possible to realize the therapeutic potential of this nanoscale multifunctional NP-coupled Ad vector system for a combination of nanotechnology and gene therapy-based treatment of cancer.

\section{CONCLUSION}

We have demonstrated the differential contribution of the AuNP on the outside and inside the cell towards hyperthermia induction. We further investigated and concluded that due to the various technical limitations at this time as discussed afore, the potential of AuNP-coupled Ad vectors for hyperthermic tumor cell ablation can only be realized with future research.

\section{ACKNOWLEDGEMENTS}

The authors would like to thank Enid F. Keyser, Flow Cytometry Core of the UAB Arthritis and Musculoskeletal Center, University of Alabama at Birmingham (supported by NIH P30 grant AR48311), for help with flow cytometry to determine cell viability. This work was supported by following grants: ECS-0424310, EPS-0447675, BES-0521036 National Science Foundation Grants (Sergey B. Mirov), W81XWH-06-1-0630, UAB Center for Women's Reproductive Health Pilot and Feasibility grant, and NCI CA13148-35 UAB CCC Junior Faculty Development Grant Program (Maaike Everts).

\section{REFERENCES}

[1] Han G, Ghosh P, Rotello VM. Multi-functional gold nanoparticles for drug delivery. Adv Exp Med Biol 2007; 620: 48-56.

[2] Kim J, Park S, Lee JE, et al. Designed Fabrication of Multifunctional Magnetic Gold Nanoshells and their application to magnetic resonance imaging and photothermal therapy. Angewandte Chemie (International ed.) 2006 Oct 30.

[3] Huang X, El-Sayed IH, Qian W, El-Sayed MA. Cancer cell imaging and photothermal therapy in the near-infrared region by using gold nanorods. J Am Chem Soc 2006; 128(6): 2115-20.
[4] O'Neal DP, Hirsch LR, Halas NJ, Payne JD, West JL. Photothermal tumor ablation in mice using near infrared-absorbing nanoparticles. Cancer Lett 2004; 209(2): 171-6.

[5] Hirsch LR, Stafford RJ, Bankson JA, et al. Nanoshell-mediated near-infrared thermal therapy of tumors under magnetic resonance guidance. Proc Natl Acad Sci USA 2003; 100(23): 13549-54.

[6] Bhattacharya R, Mukherjee P. Biological properties of "naked" metal nanoparticles. Adv Drug Deliv Rev 2008; 1289-306.

[7] Zharov VP, Letfullin RR, Galitovskaya E. Microbubblesoverlapping mode for laser killing of cancer cells with absorbing nanoparticle clusters. J Phys D: Appl Phys 2005; 38: 2571-81.

[8] Javier DJ, Nitin N, Levy M, Ellington A, Richards-Kortum R. Aptamer-targeted gold nanoparticles as molecular-specific contrast agents for reflectance imaging. Bioconjug Chem 2008; 19(6): 1309-1312.

[9] Edwards MJ, Mulley R, Ring S, Wanner RA. Mitotic cell death and delay of mitotic activity in guinea-pig embryos following brief maternal hyperthermia. J Embryol Exp Morphol 1974; 32(3): 593-602.

[10] Kampinga HH. Cell biological effects of hyperthermia alone or combined with radiation or drugs: a short introduction to newcomers in the field. Int J Hyperthermia 2006; 22(3): 191-6.

[11] Maldonado-Codina G, Llamazares S, Glover DM. Heat shock results in cell cycle delay and synchronisation of mitotic domains in cellularised Drosophila melanogaster embryos. J Cell Sci 1993; 105 (Pt 3): 711-20.

[12] Saini V, Roth JC, Pereboeva L, Everts M. Importance of viruses and cells in cancer gene therapy. Adv Gene Mol Cell Ther 2007; 1(1): 30-43.

[13] Szatmari T, Huszty G, Desaknai S, et al. Adenoviral vector transduction of the human deoxycytidine kinase gene enhances the cytotoxic and radiosensitizing effect of gemcitabine on experimental gliomas. Cancer Gene Ther 2008; 15(3): 154-64.

[14] Lamont JP, Nemunaitis J, Kuhn JA, Landers SA, McCarty TM. A prospective phase II trial of ONYX-015 adenovirus and chemotherapy in recurrent squamous cell carcinoma of the head and neck (the Baylor experience). Ann Surg Oncol 2000; 7(8): 588-92.

[15] Tagawa M, Kawamura K, Ueyama T, et al. Cancer therapy with local oncolysis and topical cytokine secretion. Front Biosci 2008; 13: 2578-87.

[16] Saini V, Zharov VP, Brazel CS, Nikles DE, Johnson DT, Everts M. Combination of viral biology and nanotechnology: new applications in nanomedicine. Nanomedicine 2006; 2(3): 200-6.

[17] Everts M, Saini V, Leddon JL, et al. Covalently linked Au nanoparticles to a viral vector: potential for combined photothermal and gene cancer therapy. Nano Lett 2006; 6(4): 587-91.

[18] Saini V, Martyshkin DV, Mirov SB, et al. An adenoviral platform for selective self-assembly and targeted delivery of nanoparticles. Small 2008; 4(2): 262-9.

[19] Maizel JV, Jr, White DO, Scharff MD. The polypeptides of adenovirus. I. Evidence for multiple protein components in the virion and a comparison of types 2, 7A, and 12. Virology 1968; 36(1): 115-25.

[20] Zharov VP, Galitovsky V, Mark V. Photothermal detection of local thermal effects during selective nanophotothermolysis. Appl Phys Lett 2003; 83: 4897-9.

[21] Martin-Fernandez M, Longshaw SV, Kirby I, et al. Adenovirus type- 5 entry and disassembly followed in living cells by FRET, fluorescence anisotropy, and FLIM. Biophys J 2004; 87(2): 131627.

[22] Rux JJ, Burnett RM. Adenovirus structure. Hum Gene Ther 2004; 15(12): 1167-76.

[23] Everts M. Thermal scalpel to target cancer. Expert Rev Med Devices $2007 ; 4(2): 131-6$

[24] El-Sayed IH, Huang X, El-Sayed MA. Selective laser photothermal therapy of epithelial carcinoma using anti-EGFR antibody conjugated gold nanoparticles. Cancer Lett 2006; 239(1): 129-35.

[25] Chilkoti A, Tan PH, Stayton PS. Site-directed mutagenesis studies of the high-affinity streptavidin-biotin complex: contributions of tryptophan residues 79, 108, and 120. Proc Natl Acad Sci USA 1995; 92(5): 1754-8

[26] Mok H, Palmer DJ, Ng P, Barry MA. Evaluation of polyethylene glycol modification of first-generation and helper-dependent adenoviral vectors to reduce innate immune responses. Mol Ther 2005; 11(1): 66-79.

[27] Hofherr SE, Shashkova EV, Weaver EA, Khare R, Barry MA. Modification of adenoviral vectors with polyethylene glycol modu- 
lates in vivo tissue tropism and gene expression. Mol Ther 2008; 16(7): 1276-1286.

[28] Brunetti-Pierri N, Philip Ng. Progress and prospects: gene therapy for genetic diseases with helper-dependent adenoviral vectors. Gene Ther 2008; 15(8): 553-60.

[29] Balogh L, Nigavekar SS, Nair BM, et al. Significant effect of size on the in vivo biodistribution of gold composite nanodevices in mouse tumor models. Nanomedicine 2007; 3(4): 281-96.

[30] Jain PK, Lee KS, El-Sayed IH, El-Sayed MA. Calculated absorption and scattering properties of gold nanoparticles of different size, shape, and composition: applications in biological imaging and biomedicine. J Phys Chem B 2006; 110(14): 7238-48.
[31] Weissleder R. A clearer vision for in vivo imaging. Nat Biotechnol 2001; 19(4): 316-7.

[32] Rivera AD, Walker CN, Bleustein C, Choi B, Poppas DP, Felsen D. Enhanced adenoviral-vector mediated gene transfer using human albumin solder. Lasers Surg Med 2002; 30(4): 313-9.

[33] Shayakhmetov DM, Eberly AM, Li ZY, Lieber A. Deletion of penton RGD motifs affects the efficiency of both the internalization and the endosome escape of viral particles containing adenovirus serotype 5 or 35 fiber knobs. J Virol 2005; 79(2): 1053-61.

(C) Saini et al.; Licensee Bentham Open.

This is an open access article licensed under the terms of the Creative Commons Attribution Non-Commercial License (http://creativecommons.org/licenses/by-nc/3.0/) which permits unrestricted, non-commercial use, distribution and reproduction in any medium, provided the work is properly cited. 